\title{
The Study of the Distribution of Carbon Black Filler in Rubber Compounds by Measuring the Electrical Conductivity
}

Dana Bakošová

Faculty of Industrial Technologies in Púchov, Alexander Dubček University of Trenčín. I. Krasku 491/30, 02001 Púchov. Slovakia. E-mail: dana.bakosova@fpt.tnuni.sk

\begin{abstract}
This study deals with distribution of carbon black fillers in rubber compounds using electrical conductivity measurements. Three rubber compounds samples were heated in resistive furnace in temperature interval $40-80^{\circ} \mathrm{C}$ and electrical current was measured, while voltage was constant. All samples showed a decrease in electrical conductivity with decreasing temperature, which is characteristic of semiconductors and insulators. On the other hand the large variance of activation energy can be seen for electric transport in different areas of the temperature dependence of the direct electrical conductivity. These quasi-linear areas were selected, linear regression was used and corresponding activation energy was calculated. The number of the identified areas was changing, and hence the number of conductivity mechanisms was changing as well. Clearly it can be concluded that all three samples show inhomogeneity of distribution of filler, which can be seen from the variance of values of the activation value of electric transport.
\end{abstract}

Keywords: Electrical conductivity, Rubber compound, Carbon black filler, Activation energy

\section{Introduction}

Electrically conductive composites are widely used in electronic sectors in power distribution, audio, and telephone application, as packaging and semi conductive polymeric materials due to their good weather resistance, good electrical properties and good ageing resistance. The preparation of electrically conductive polymer composites filled with conductive fillers has already been reported by several researchers [1]. The incorporation of filler in to a rubber for instance not only influences the mechanical and electrical properties of the final product but also decreases the cost of the end product. The reinforcement of an elastomer by filler is associated with a strong interaction between a rigid phase and a soft solid phase, which may be of physical or chemical type [2]. Carbon black filled rubber compound consists of two interpenetrated networks: the carbon black network and the polymer network. From an electrical point of view, these two networks have very different properties. Polymer chains form a very resistive network while carbon black forms a conductive network. These differences in properties should allow one to use carbon black as a probe for a variety of electrical measurements [3].

\section{Material and methods}

\subsection{Material}

Rubber compound is mixture of natural and synthetic rubber with many other additives, which effect on processability, allow vulcanization and determine properties of vulcanite.

Additives in rubber compounds:

Fillers - in general change all properties of unvulcanised_compounds as well as vulcanite. They modify processability, density, strength, tensibility, technical module, dynamical properties etc. Some properties change monotonously with increasing amount of fillers, for example hardness [4]. Other properties improve until maximum, than degrade with further increasing amount of fillers (strenght). The fillers are divided into active and inactive fillers. Active fillers improve some important properties like strength and module. Then Fillers are divided into the white fillers and carbon black fillers. White fillers are non - carbon black fillers with different chemical structure and features. White fillers are for example silicate oxide, calcium silicate, kaolin. Effect of fillers depends on the size and the shape of their particles and surface activity [5].

Activators of vulcanization - are anorganic and organic substances that activate effect of vulcanizing agents. Activators increase crosslinking effect of vulcanizing system during sulphur vulcanization. Mostly used anorganic substances are metal oxides (calcium oxide, zinc oxide). Organic substances that are used include long chain fatty acids and their salts, weak amines, aminoalcohols.

Vulcanizing agents - are substances that allow chemical reaction during which cross-links between molecule chains of rubber hydrocarbons are formed. Strenght, thermal resistance against both low and high temperatures, hardness and flexibility are improved. Tensibility and permanent deformation are decreased. The most common vulcanization agents are sulphur, selenium, tellurium, peroxides, metal oxides, chinondiooxides, diamines, and diisocyanates.

Accelerators of vulcanization - are one of the most important parts of rubber compounds. Together with vulcanizing agents affect process of vulcanization and properties of vulcanizes (resistance against oxidation, heat resistance and abrasion resistance). Their main function is speed up crosslinking between elastomer chains [6].

Stabilizers - include antioxidants, antizonates and protective waxes. They slow down changes of mechanical properties (strength, tensibility, module, hardness) due to the aging. The character and the rate of these changes depend on atmospheric effects, effect of oxygen, ozone, thermal and light energy [7].

Softeners - are additives that decrease rigidity of rubber compounds, thus modify their processability (mixing, 
rolling, extrusion). They include substances with different chemical properties and consistency. These effect can be fulfilled by different low molecule liquids or rigid substances if they are mixable with rubber.

Additional rubber additives include adhesive and stiffening resins plasticizing agents, adhesive agents and pigments [8].

\subsection{Electrical properties of polymers}

Polymers, like other substances, consist of structural elements that have their electrical charge with ability to adjust to effect of outside electric field. Movement of these fundamental structural charges determinates all electrical properties. Due to explanation its useful to compere electrical properties of metals and polymers. Metals ate typical conductors of electric current. They have regular atomic structure, where valence electrones can move freely [9]. If metal conductor is affected by outside electric field, continuous flow of electrones is caused. Therefore metals are characterized by high electric conductivity [10]. On the other hand, valence electrones of polymers form covalent bonds, thus they cannot move freely. If the resulting electrical dipoles are affected by outside electric field, they can deflect in limited measure from their equilibrium positions and orientate in direction of this field. Existence of flexible attractive forces hinders movement of the electric charges and displays in ability of polymers to accumulate electrical energy in form of potential energy that can be obtained back, after electric field is removed. Thus polymers behave as typical insulators. Ability of the insulator to accumulate electrical energy is characterized by its permittivity. Orientated movement of the fundamental dipoles of the polymer structures is limited by high viscosity of environment. The dipoles do not follow changes of electric field immediately, but with a certain time delay, that shows as dielectric loss of accumulated energy. Polymers are used in electrotechnics mainly as insulators due to their properties. However certain min- imal electric conductivity have to be considered for polymer products due to the presence of ionic impurities, humidity/moisture, structural defects and in homogeneities that can be also caused by the used fillers. Electric conductivity of pure polymers is usually very low [11]. The presence of micro in homogeneities in the structure allows possibility of the formation of free electric charges (for example interface between amorphous and crystallise phase). However low electric conductivity can be explained by presence of ionic impurities. Mechanism of transfer of ionic charges is similar to the diffusion of gases that is also suggested by similar activation energy of conductivity and permeability of gases. Absolute insulator is just vacuum. Others real insulators, including polymers, have small conductivity, that is caused by movement of electrons and ions.

\section{Experimental part}

Measurement of direct electrical conductivity of the rubber compounds was made with apparatus that consisted of the piko amperemeter Amplifier E 316, a power supply, conductive cables an electrical resistive furnace and a sample holder. (Fig. 1)

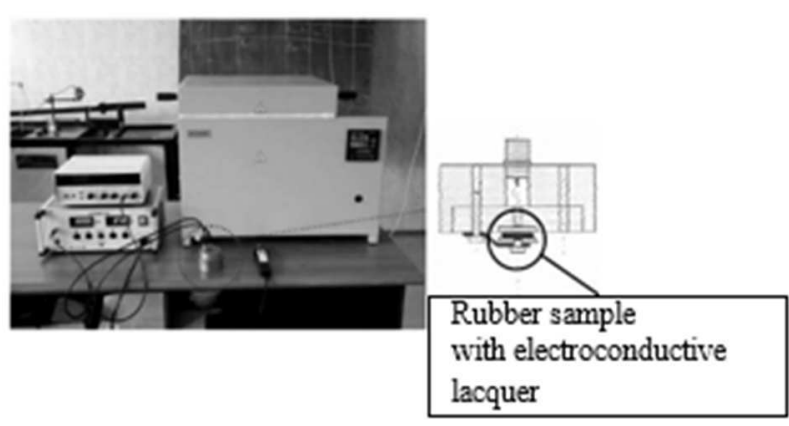

Fig. 1 Apparatus for measuring the DC conductivity

Tab. 1 Chemical composition of rubber compounds

\begin{tabular}{|c|c|c|c|}
\hline \multirow{2}{*}{ Components } & \multicolumn{3}{|c|}{ Dose in PHR } \\
\cline { 2 - 4 } & Compound 1 & Compound 2 & Compound 3 \\
\hline SULPHUR & $1-2$ & $1-2$ & $2-3$ \\
\hline SULFENAX & $1-1.5$ & $1-2$ & $1-2$ \\
\hline SKD 2 & $20-30$ & $30-40$ & - \\
\hline BUNA & $50-60$ & - & $130-145$ \\
\hline KRALEX & - & - & - \\
\hline ULTRASIL (Silica) & $20-40$ & $60-90$ & $85-100$ \\
\hline VULCAN (Carbon black) & $25-45$ & $5-20$ & $4-9$ \\
\hline ZnO & $2.8-3.5$ & $2.2-2.8$ & $1-2$ \\
\hline DUSANTOX & $1-2$ & $1-2$ & $1.3-1.6$ \\
\hline FLECTOL & $1.5-2.5$ & $1.5-2.5$ & $1.7-2.2$ \\
\hline STEARIN & $1.7-2.2$ & $1.0-1.5$ & 35.0 \\
\hline pound & 20.5 & 6.0 & - \\
\hline The percentage of silica in the compound & 13.5 & 30.0 & \\
\hline
\end{tabular}


Formula for calculating thermal dependence of direct electrical conductivity:

$$
\sigma=\sigma_{0} e^{-\frac{E a}{2 k T}}\left[\Omega^{-1} \mathrm{~m}^{-1}\right]
$$

where $k$ is Boltzmann constant, $T$ is temperature, $\sigma_{0}$ is pre-exponential factor, $E a$ is activation energy.

The goal of this measurement was to determined sensitivity the measuring method on homogeneity of the distribution of the fillers.

Three rubber compounds that were shaped as square prism with area of the base $100 \mathrm{~cm}^{2}$ and height $2 \mathrm{~mm}$ were examined. From these samples we cut from different places three circle samples with diameter $12 \mathrm{~mm}$. (1A, $1 \mathrm{~B}, 1 \mathrm{C}$ - compound 1, 2A, 2B, 2C-compound 2, 3A, 3B and $3 \mathrm{C}-$ compound 3 ). In the table 1 there is listed a chemical composition of compounds used for the samples.

Samples were heated in the resistive furnace in temperature interval $40-80^{\circ} \mathrm{C}$ and electrical current was measured, while voltage was constant. Then electrical conductivity and activation energy was calculated in different areas of thermal dependence of direct electrical conductivity. Conductivity characteristics and calculated values of activation energy for the three samples made from the compound 1 are represented in the figures 2 to 4. In the figures 5 to 7 there are displayed thermal dependence of direct electrical conductivity and values for activation energy of the samples made from the compound 2 .

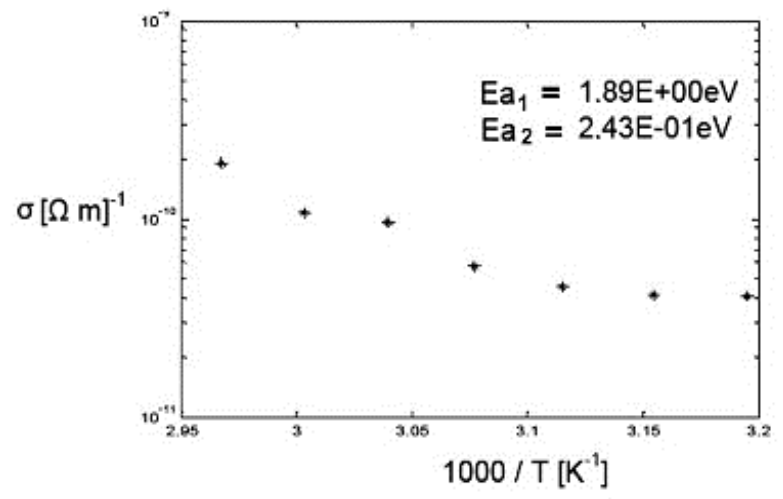

Fig. 2 The temperature dependence of electrical conductivity - compound 1 sample $1 \mathrm{~A}$

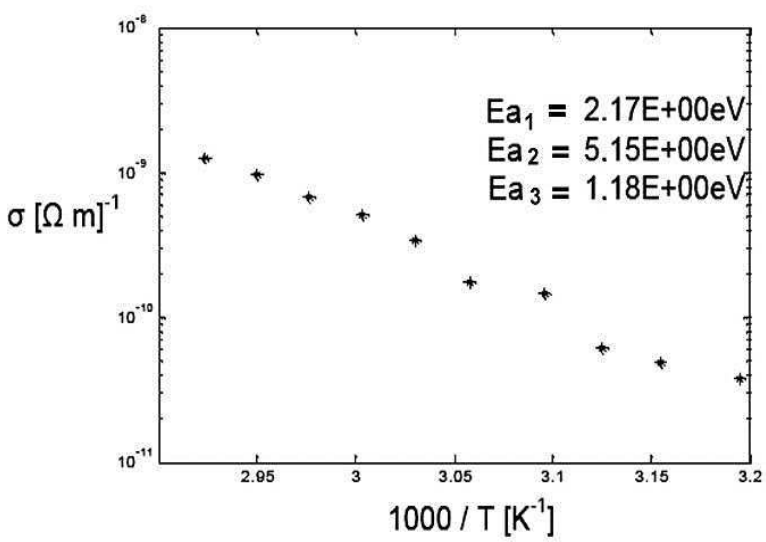

Fig. 3 The temperature dependence of electrical conductivity - compound 1 sample $1 B$

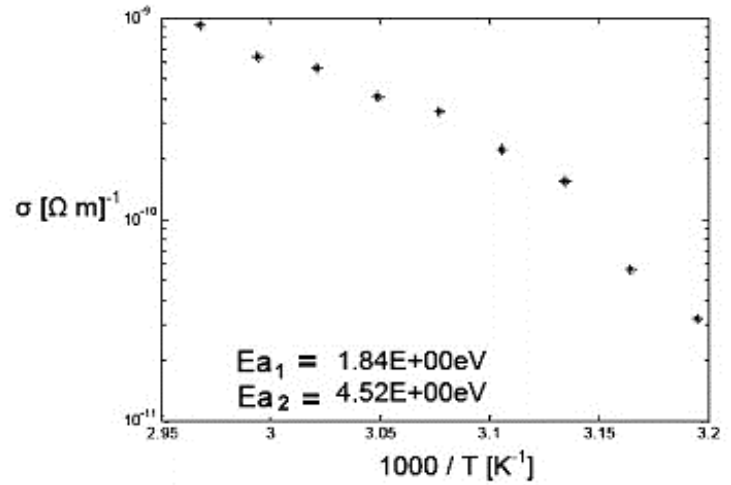

Fig. 4 The temperature dependence of electrical conductivity - compound 1 sample $1 C$

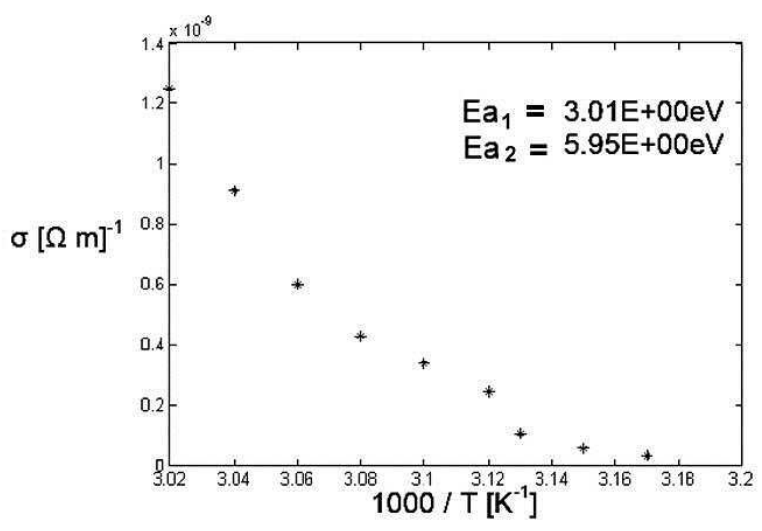

Fig. 5 The temperature dependence of electrical conductivity - compound 2 sample $2 \mathrm{~A}$

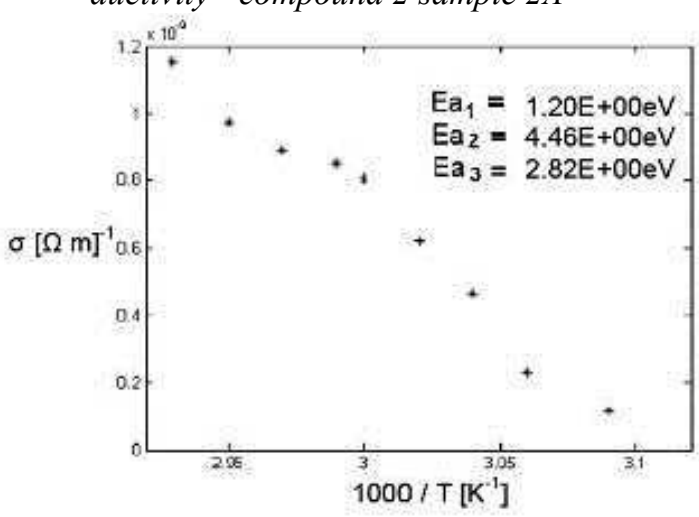

Fig. 6 The temperature dependence of electrical conductivity - compound 2 sample $2 B$

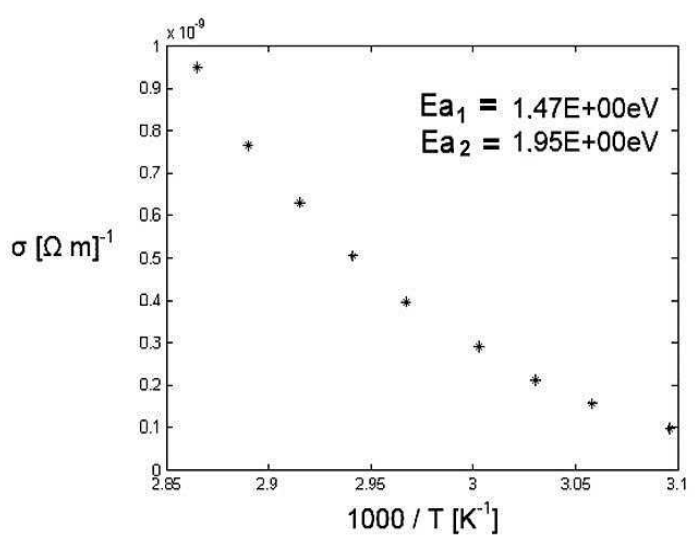

Fig. 7 The temperature dependence of electrical conductivity - compound 2 sample $2 \mathrm{C}$ 


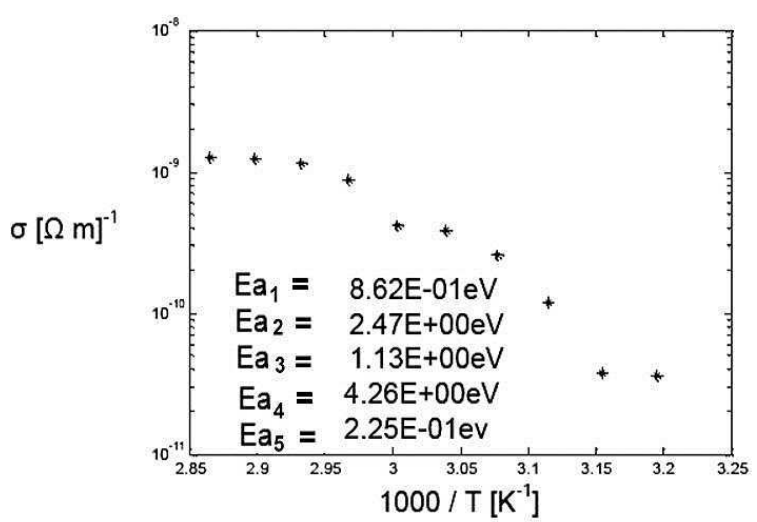

Fig. 8 The temperature dependence of electrical conductivity - compound 3 sample $3 A$

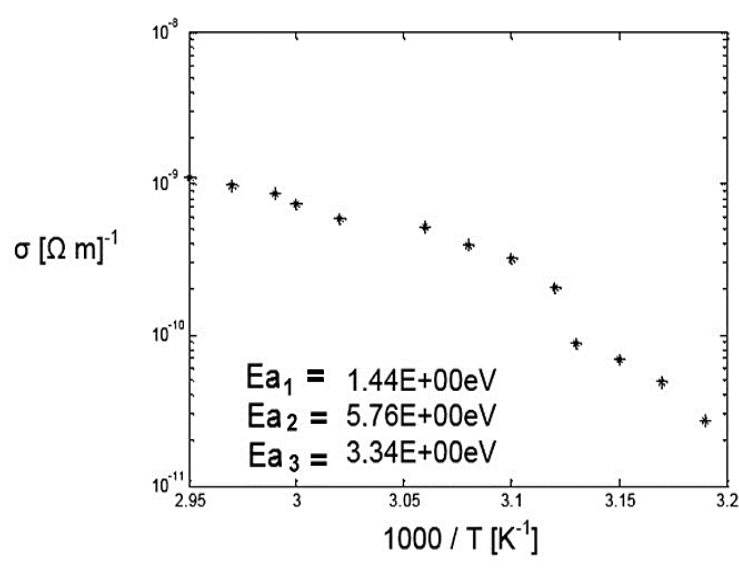

Fig. 9 The temperature dependence of electrical conductivity - compound 3 sample $3 B$

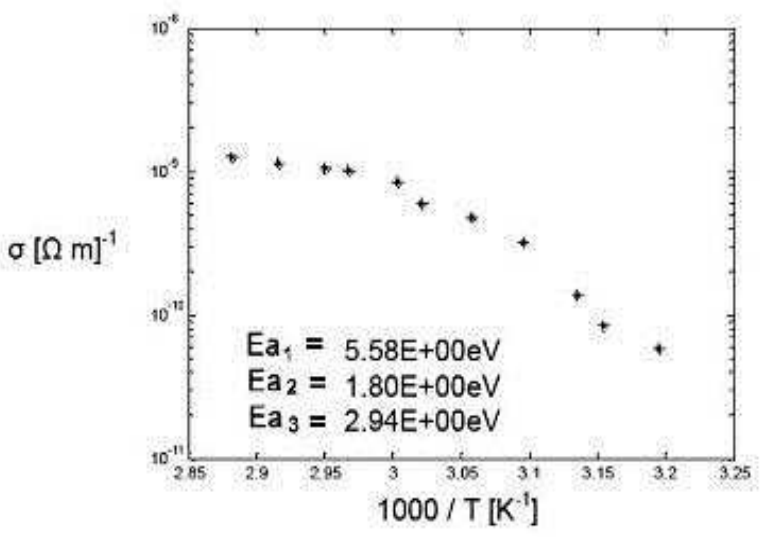

Fig. 10 The temperature dependence of electrical conductivity - compound 3 sample $3 C$

Conductivity dependence on thermal coefficient $1000 / \mathrm{T}$ and activation energy for the compound 3 are in the figures 8 to 10 . This compound showed the biggest difference between values of individual samples. The highest value of activation energy in the area 1 was recorded for the sample $3 \mathrm{C}$, which significantly differed from the samples $1 \mathrm{C}$ and $2 \mathrm{C}$. Measurements showed, that dispersion of black carbon filler in the compound 3 was of worse quality compared to the compounds 1 a 2 .

\section{Results and discussion}

All samples showed a decrease in electrical conductivity with decreasing temperature, which is characteristic of semiconductors and insulators. On the other hand the large variance of activation energy can be seen for electric transport in different areas of the temperature dependence of the direct electrical conductivity. These quasi-linear areas were selected, linear regression was used and corresponding activation energy was calculated. The number of the identified areas was changing, and hence the number of conductivity mechanisms was 3 changing as well. Clearly it can be concluded that all three samples show inhomogeneity of distribution of filler, which can be seen from the variance of values of the activation value of electric transport.

\section{Conclusions}

In general, rubbers are insulators because the atoms in the rubber chain are covalently bonded. In the covalent bonded molecules of organic carbon compounds, there is no scope of delocalization of the valence electrons. Consequently, the electron carrier path is not available. One of the important methods to form carrier path in an insulating rubber matrix is the incorporation of conductive additives like carbon blacks, carbon fibers, metals or metal oxides. Among different types of conductive additives, carbon blacks are the most widely used for rubber matrix. They not only provide high degree of conductivity, but also offer good reinforcement to the rubber matrix. Rubber/carbon black conductive composites are widely used for rubber contact switches, floor heating, electromagnetic interference shielding and various other electronic and electrical applications. The results presented in this paper lead to the conclusion that electrical conductivity measurements can provide a significant insight into the composition of a rubber compound. The final electrical conductivity of the compound will depend on the carbon black loading, carbon black grade and its degree of dispersion. As it was demonstrated in several sections of this paper the electrical measurements can assess information about filler distribution/dispersion. In addition the polymer dispersion potential can be evaluated.

\section{Acknowledgement}

This paper deal was supported by the Slovak Grant Agency KEGA 007TnUAD-4/2017, VEGA grant No. 1/0649/17 and resulted from the project "Center for quality testing and diagnostics of materials", ITMS code 26210120046 relating to the Operational Program Research and Development funded from European Fund of Regional Development.

\section{References}

[1] SAU K. P., CHAKI T. K., KHASTGIR D. (1999). Electrical and mechanical properties of conducting carbon black filled composites based on rubber and rubber blends. In: Journal of Applied Polymer Science, 71, 887-895. 
[2] MICUSIK M., OMASTOVA M., PROKES J., KRUPA I. (2006). Mechanical and electrical properties of composites based on thermoplastic matrices and conductive cellulose fibers. In: Journal of Applied Polymer Science, 101, 133-142.

[3] PRAMANIK P. K., KHASTGIR D., SAHA T. N. (1991). Electromagnetic interference shielding by conductive nitrile rubber composites containing carbon fillers. In: Journal of Elastomers and Plastics, 23, 345-361.

[4] POSPÍCHAL, M., DVOŘÁKOVÁ, R., STUDENÝ, Z., POKORNÝ Z. (2015). Influence of Initial Carbon Concentration on Nitride Layers. In: Manufacturing Technology, Vol. 15, No. 5, pp. 889-893.

[5] GROSSMAN, R. E., ED. (1997). The Mixing of Rubber, In: Chapman \& Hall, London.

[6] PREKOP, Š., VÁRKOLY, L., KUČMA, A., ĎURIŠ, Š., FEDOROVÁ, E., MATUŠČINOVÁ, A.,MICHÁLEK, J.(1987). Rubber Technology I., In: University of Žilina, ISBN 80-7100-483-9, Žilina.
[7] FRANTA, I., ED. (1989). Elastomers and Rubber Compounding Materials, In: Elsevier Science Publishers, New York.

[8] JIACHUAN, Y. et al. (2016). Contact Analysis of Silicone Rubber Rectangular Ring in the Automatic Tighten Assembly. In: Manufacturing Technology. Vol. 16, No. 3, pp. 648-653.

[9] XIUSHU, T. et al. Research on Mechanical and Electrical Properties of Carbon Nanotubes Reinforced Cementbased Materials. In: Manufacturing Technology, Vol. 17, No. 3, pp. 407-411.

[10] DAS N. C., CHAKI T. K., KHASTGIR D., CHAKRABORTY A. (2002). Electrical and mechanical properties of conductive carbon black filled EVA, EPDM and their blends. In: Kautschuk, Gummi, Kunststoffe, 55, 300-306.

[11] MAHAPATRA S. P., SRIDHAR V., CHAUDHARY R. N. P., TRIPATHY D. K. (2008). AC conductivity and positive temperature coefficient effect in microcellular EPDM vulcanizates. In: Polymer Composites, 29, 1125-1136. 